\title{
Optimalisasi Fungsi BUMDES Melalui Inovasi dan Manajemen Organisasi Sebagai Upaya Meningkatkan Kemandirian Desa
}

\author{
Arif Fajar Wibisono, Bagus Panuntun \\ Fakultas Ekonomi Universitas Islam Indonesia \\ Email:ariffajarwibisono@uii.ac.id, bagus.panuntun@uii.ac.id
}

\begin{abstract}
ABSTRAK
Pendirian BUMDes merupakan salah satu upaya pemerintah untuk menjadikan lembaga ekonomi sekaligus lembaga sosial yang bertujuan untuk meningkatkan kesejahteraan masyarakat Desa dan memupuk modal sosial masyarakat Desa. Namun hingga saat ini masih banyak fungsi dan peran BUMDes yang belum dirasakan manfaatnya oleh masyarakat. Hal ini diakibatkan berbagai macam kondisi, diantaranya masih rendahnya pengetahuan pengelolaan organisasi dan sedikitnya inovasi usaha yang dikembangkan oleh BUMDes. Dikarenakan keadaaan tersebut maka BUMDes belum mampu menjadi sumber ekonomi bagi organisasinya apalagi bagi masyarakat secara keseluruhan. Masih banyak usaha BUMDes yang belum menghasilkan keuntungan bahkan masih harus di subsidi oleh pemerintah Desa. Maka tidak heran jika masih banyak BUMDes yang hanya tinggal nama saja tidak memiliki kegiatan ekonomi sama sekali. Tidak terkecuali 8 BUMDes dari 16 Desa di Kecamatan Ngablak Jawa Tengah, dari jumlah tersebut hanya 4 yang memiliki kegiatan ekonomi namun belum optimal menghasilkan keuntungan bagi organisasi maupun bagi masyarakat. Dengan adanya kondisi tersebut maka pengabdian ini dilaksanakan dengan berbagai strategi agar fungsi dan peran BUMDes yang ada di kecamatan Ngablak menjadi lebih optimal dan harapannya dapat memberikan manfaat bagi organisasi dan masyarakat secara keseluruhan. Strategi yang digunakan yaitu penguatan pengelola organisasi, manajemen organisasi dan pengembangan inovasi.
\end{abstract}

Kata Kunci: BUMDEs, manajemen organisasi, inovasi

\section{ABSTRACT}

Establishment of Village-Owned Enterprise (BUMDes) is one of the government's efforts to make economic institutions as well as social institutions that aim to improve the welfare of rural communities and foster social capital of rural communities. But until now there are still many functions and roles of BUMDes that have not been felt by the community. This is due to various conditions, including the low level of organizational management knowledge and the lack of business innovation developed by BUMDes. Due to these conditions, BUMDes has not been able to become an economic source for the organization especially for the community as a whole. There are still many BUMDes businesses that have not yet made a profit even they still have to be subsidized by the village government. So do not be surprised if there are still many BUMDes that only have names but do not have any economic activity. There are no exception 8 BUMDes from 16 villages in Ngablak subdistrict, Central Java, of which only 4 have economic activities but are not yet optimal in producing profits for the organization and the community. Given these conditions, this service is carried out with a variety of strategies so that the functions and roles of the BUMDes in Ngablak subdistrict become more optimal and hopefully can provide benefits to the organization and the community as a whole. The strategy used is strengthening organizational management, organizational management and innovation development.

Keywords: village-owned enterprise, BUMDes, organizational management, innovation 
Sejak disahkannya UU Desa No. 6 Tahun 2014 tentang Desa, harapan terwujudnya kemandirian Desa semakin kuat. Salah satu upaya dalam undang-undang tersebut adalah berdirinya Badan Usaha Milik Desa (BUMDes). BUMDes diharapkan dapat menjadi lembaga ekonomi sekaligus lembaga sosial yang bertujuan untuk meningkatkan kesejahteraan masyarakat Desa dan memupuk modal sosial masyarakat Desa. Peningkatan kesejahteraan masyarakat Desa berupa peningkatan pendapatan, pengurangan pengangguran, pengentasan kemiskinan dan berkurangnya kesenjangan antar Desa.

Hingga November 2018 jumlah Badan Usaha Milik Desa telah mencapai 41 ribu unit di seluruh Indonesia. Puluhan ribu BUMDes ini tersebar di 74.957 desa yang ada di Indonesia. (www.republika.co.di). Masalahnya hingga sampai saat ini, berbagai data menyebutkan bahwa sebagian besar BUMDes masih sebatas berdiri dan belum memiliki aktivitas usaha yang menghasilkan. Selain itu karena rendahnya pemahaman Kepala Desa atas berdrinya BUMDes ini maka sebagian besar malah layu sebelum berkembang. Tidak terkecuali yang terjadi di Kecamatan Ngablak Kabupaten Magelang, disini data BUMdes menurut website Kementerian Desa, Pembangunan Daerah Tertinggal, dan Transmigrasi (Kemendes PDT) tercatat 8 BUMDes dari 16 desa yang ada. Namun setelah pengabdi melakukan observasi lapangan ternyata hanya terdapat 4 BUMDes yang cukup aktif. Namun permasalahannya kebanyakan usaha yang dilakukan hanya sebatas pengeloaan simpan pinjam, dan ternyata simpan pinjam tersebut banyak yang macet karena permasalahan ekonomi peminjam. Kondisi tersebut menyebabkan kekurangan cash flow, sehingga banyak BUMDes yang harus menambah terus modalnya. Minusnya cash flow jika dilihat dari perspektif bisnis sangat tidak baik, karena akan menjadikan usaha tersebut gulung tikar.

Kecamatan Ngablak Kabupaten Magelang Jawa Tengah, merupakan daerah dataran tinggi yang dikeliling gunung Merbabu, gunung Andong dan gunung Telomoyo. Daerah ini memiliki banyak potensi lokal yang dapat dikomersialisasi melalui inovasi kegiatan BUMDES. Sebagai daerah dataran tinggi di kaki pegunungan salah satu keunggulan yang cukup potensial adalah 
kesuburan tanahnya dan potensi pemandangan alam yang cukup indah. Kecamatan Ngablak memiliki 16 Desa yang tersebar diantara luasnya wilayah yang mencapai 43,80 km persegi dengan jumlah penduduk 38.738 (data BPS tahun 2015). Penduduk desa Ngablak sebagian besar mata pencahariannya adalah petani sayur dan peternak hewan, hal ini cukup wajar mengingat potensi kesuburan tanah daerah tersebut. Namun pertanian, peternakan dan wisata daerah tersebut belum dioptimalkan karena masih minimnya pengetahuan dan inovasi dalam pengelolaannya. Harapan dengan adanya pengabdian ini, pemrintah Desa dan warga masyarakat menjadi lebih terbuka untuk mengembangkan BUMDes dengan berbagai jenis inovasi dari kekayaan lokal yang dimilki desa tersebut. Sehingga BUMDes benar-benar menjadi lembaga ekonomi yang mampu mensejahterakan masyarakatnya sehingga dapat mewujudkan Desa yang madiri.

\section{METODE}

Guna meningkatkan fungsi dan kinerja BUMDes menuju kemandirian desa maka metode yang digunakan dalam pengabdian ini dapat digambarkan dalam diagram alir berikut ini :

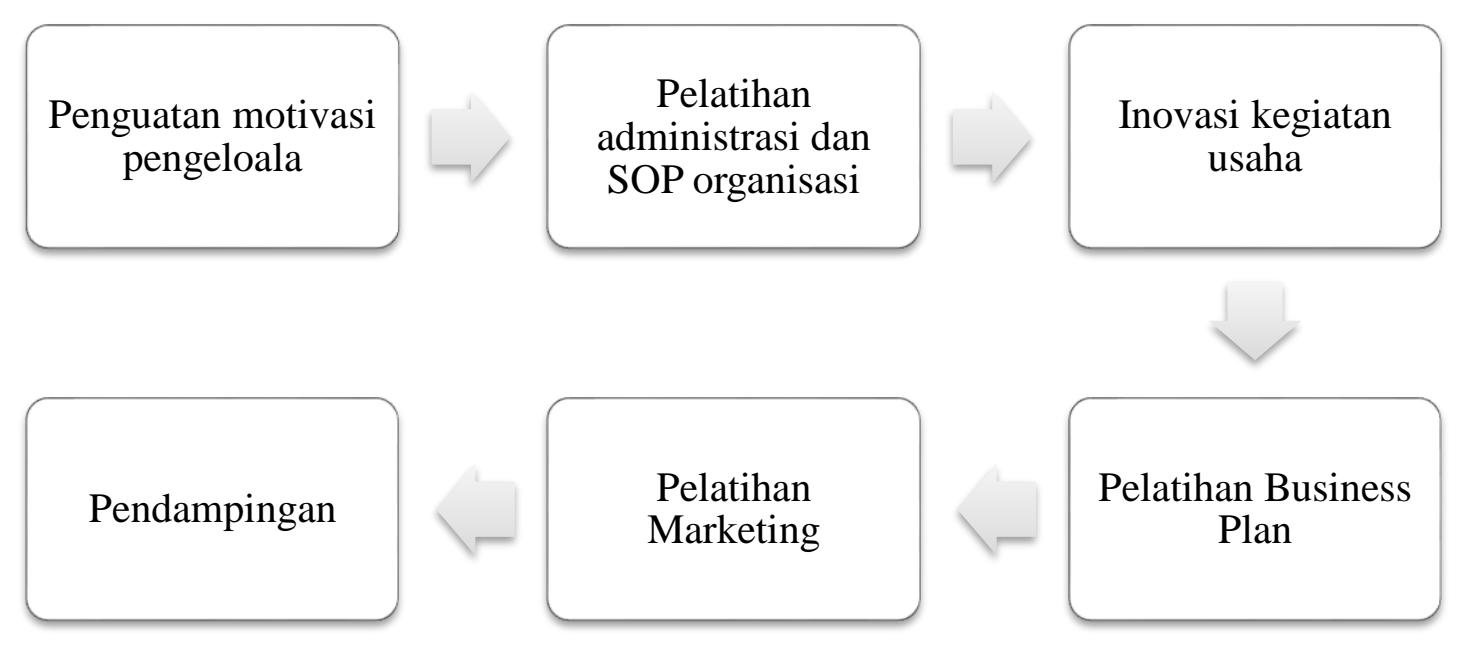

Gambar 1. Diagram Alir Proses Pengabdian

1. Penguatan motivasi pengelola

Mitra akan dimotivasi dari dalam diri bagaimana mengelola organisasi yang efektif. Materi-materi terkait motivasi internal dan organisasi akan diberikan oleh pemateri 
dengan konsep forum group discussion terkait permasalahan yang terjadi dan feedback berupa pemberian solusi dan permasalahannya.

2. Pelatihan Administrasi dan SOP (Standar Operasional Prosedur) Organisasi

Mitra akan diberikan materi-materi tentang hal-hal mendasar tentang organisasi. Mitra akan dijelaskan terkait menyusun konsep Anggaran Dasar, Anggaran Rumah Tangga, administrasi organisasi dan administrasi keuangan. Dengan diadakanya pelatihan ini mitra akan mampu membuat SOP dan melaksanakan administrasi organisasi dengan baik.

3. Inovasi Kegiatan Usaha

Pelatihan pengembangan inovasi dilaksanakan untuk meningkatkan berbagai macam potensi usaha yang dapat dilaksanakan oleh BUMDES. Materi pelatihan salah satunya bagaimana merancang business plan yang baik kemudian menghitung harga pokok produksi dan bagaimana produksi yang baik dan efisien dalam menghasilkan keuntungan.

4. Pelatihan Marketing

Penyampaian materi manajemen pemasaran di sini dititik beratkan tentang bagaimana mitra mampu melakukan perencanaan pemasaran, menentukan segmen pasar, menentukan strategi pemasaran. Penekanannya adalah menjalin komunikasi dengan konsumen agar menjadi pelanggan setia, pangsa pasar bertambah melalui pemberian informasi produk dan variasinya sehingga lebih mendekatkan produsen kepada konsumen melalui berbagai media yang memungkinkan.

5. Pendampingan

Pendampingan ini dilaksanakan untuk mengimplementasikan pelatihan-pelatihan yang telah didapat oleh mitra. Pendampingan dilakukan oleh dosen dan mahasiswa secara berkelompok bersama mitra dengan rancangan seperti pada tabel berikut : 


\begin{tabular}{|c|l|l|l|}
\hline Pendampingan & \multicolumn{1}{|c|}{ Aspek } & \multicolumn{1}{|c|}{ Topik } & \multicolumn{1}{c|}{ Luaran } \\
\hline 1 & SOP Organisasi & $\begin{array}{l}\text { Perencanaan dan } \\
\text { penyusunan SOP organisasi } \\
\text { yang efektif }\end{array}$ & $\begin{array}{l}\text { SOP organisasi yang } \\
\text { terdokumentasi }\end{array}$ \\
\hline 2 & $\begin{array}{l}\text { Adminitrasi } \\
\text { Organsiasi }\end{array}$ & $\begin{array}{l}\text { Pelaksanakan administrasi } \\
\text { yang tepat dalam organisasi }\end{array}$ & $\begin{array}{l}\text { Dokumen administrasi } \\
\text { yang diperlukan organisasi }\end{array}$ \\
\hline 3 & Inovasi produk & $\begin{array}{l}\text { Mengembangkan inovasi- } \\
\text { inovasi berbagai macam } \\
\text { jenis produk yanhg dapat } \\
\text { dikomersialisasi oleh } \\
\text { BUMDES }\end{array}$ & $\begin{array}{l}\text { Inovasi produk -produk } \\
\text { baru BUMDES. }\end{array}$ \\
\hline 4 & Business Plan & $\begin{array}{l}\text { Pembuatan business plan } \\
\text { yang terukur }\end{array}$ & $\begin{array}{l}\text { Mitra mampu membuat } \\
\text { business plan }\end{array}$ \\
\hline
\end{tabular}

Tabel 1. Pendampingan mitra

\section{HASIL DAN PEMBAHASAN}

Kegiatan ini diawali dengan pemberian materi terkait motivasi organisasi dan konsep administrasi BUMDes yang tepat, bentuk dari dukungan pemerintah desa pada kegiatan ini yaitu secara langsung sekretaris Camat Ngablak berkenan membuka dan mendampingi acara ini. Acara ini dihadiri dari seluruh perwakilan BUMDes yang aktif. Kegiatan ini juga mengajak beberapa mahasiswa yang nantinya akan diterjunkan untuk mendampingi operasionalisasi pendampingan di BUMDes tersebut.
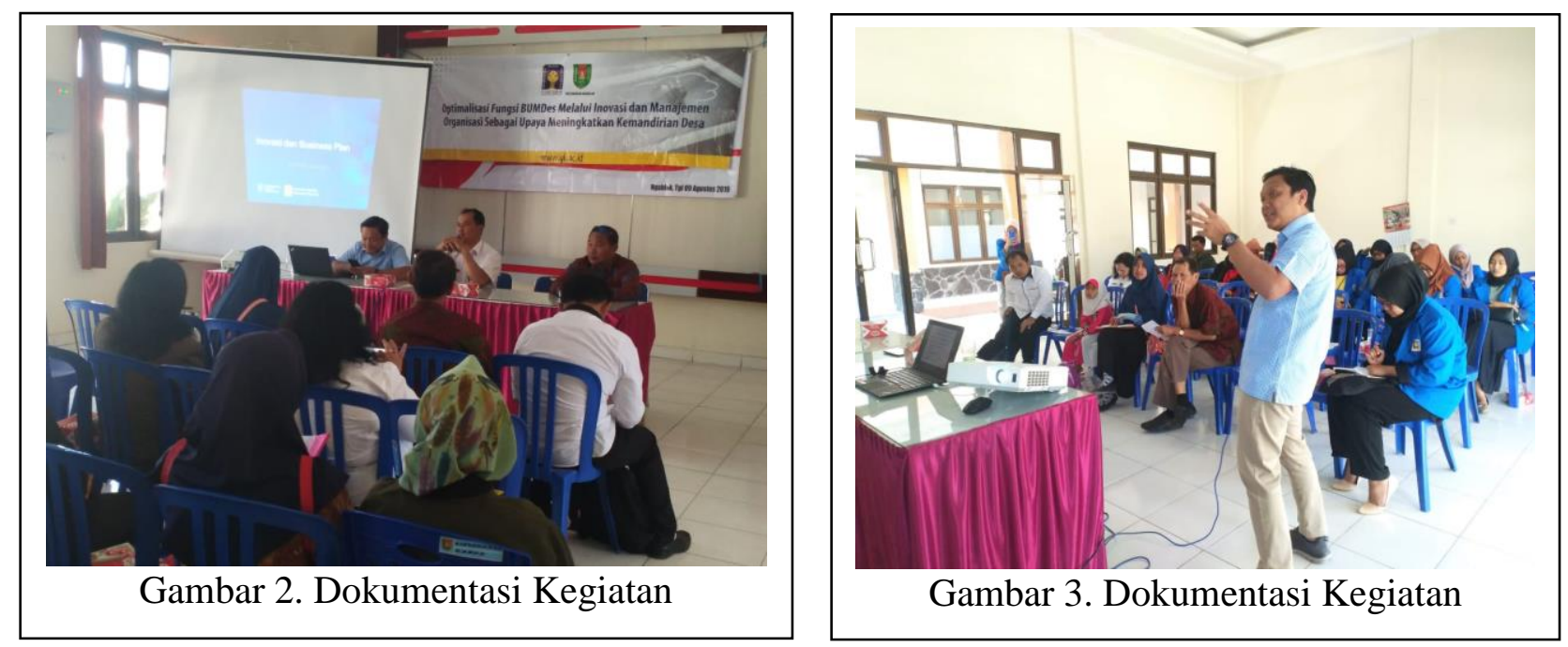

Pada agenda ini dapat disimpulkan bahwa sebagian besar pengurus BUMDes masih sangat membutuhkan informasi terkait pengelolaan administrasi. Hal ini dibuktikan dengan banyaknya 
pertanyaan yang ditanyakan terkait bagaimana mengeloala organisasi yang baik khususnya pada BUMDes mereka. Hingga saat ini pengelola masih sangat tergantung dengan catatan-catatan sederhana yang sangat terbatas, seperti misalnya mencatat pengeluaran uang masih banyak yang mengandalkan catatan pada selembar kertas saja. Mereka akan memindah catatannya ke dalam buku yang lebih besar jika sudah mulai menumpuk banyak pengeluarnnya. Dari kegiatan pengabdian yang sudah dilakukan maka dapat di jelaskan bahwa para pengelola sudah mengerti dan memahami bahwa pengelolaan BUMDes yang baik yaitu :

1. Organisasi harus memerlukan struktur organisasi yang menggambarkan bidang pekerjaan yang mencakup seluruh organisasi tersebut. Termasuk didalamnya bagaimana pola hubungan kerja antar bagiannya (instruksi, konsultatif, dan pertanggungjawaban). Bentuk aplikasi konsep ini pengelola BUMDes mampu menyusun jobdescription (gambaran pekerjaan) untuk memperjelas peran masing-masing orang atau bagian. Dengan demikian, tugas, tanggungjawab, dan wewenang pemegang jabatan tidak terjadi duplikasi yang memungkinkan setiap jabatan/pekerjaan yang terdapat di dalam BUMDes. Selain itu pengelola BUMDes juga lebih memahami bahwa sistem koordinasi yang paling utama adalah dengan Pemerintah Desa khususnya kepala desa setempat. Karena bagaimanapun juga kepala desa menjadi salah satu motor penggerak utama kesuksesan kinerja BUMDes.

2. Organisasi harus memilki pedoman kerja yang jelas, maka keberadaan AD/ART sangat diperlukan sbagai rujukan kegiatan organisasi. Termasuk didalamnya bagaimana membuat kontrak kerja sama dengan pihak ketiga terkait transaksi jual beli atau simpan pinjam yang saling menguntungkan.

3. Organisasi yang baik harus memperhatikan kesejahteraan pengelolanya, maka dengan adanya kegiatan ini para pengelola organisasi mampu menyusun sistem penggajian dan pengupahan yang tepat. Sistem penggajian dan pengupahan ini menjadi salah satu alat memotivasi para pengelola agar target capaian organisasi dapat segera direalisasikan. 
4. Organisasi publik harus mengutamakan transparansi pertanggungjawab baik kinerjanya maupun aktivitas lainnya. Dengan sistem ini maka keberadaan BUMDes menjadi lebih jelas sehingga mampu meningkatkan kepercayaan masyarakat bahwa organisasi tersebut menjadi lembaga ekonomi desa yang mampu mensejahterakan dan meningkatkan kemandirian desa.

5. Penyusunan rencana usaha yang jelas dan terukur baik yang dibuat dalam periode jangka pendek maupun jangka panjang. Rencana usaha ini juga termasuk didalamnya memuat ide ide yang kreatif dan inovatif sesuai dengan kondisi yang ada di masyarakat sekitar. Ide tersebut tentu saja mampu mengangkat kekayaan lokal menjadi salah satu komiditi usaha yang menguntungkan. Rencana ini dapat dijadikan pedoman yang jelas kegiatan apa yang harus dilaksankan sekarang atau nanti. Rencana ini juga menajadi acuan target yang harus dicapai dalam jangka panjang maupun jangka pendek, termasuk didalamnya ukuran kinerja yang menjadi target capainnya.

6. Mampu melakukan perhitungan usaha yang menguntungkan, pengelola BUMDes menjadi lebih paham bahwa margin laba bukan satu-satunya ukuran yang menentukan bahwa usaha tersebut menguntungkan. Tetapi kinerja sebuat unit bisnis juga melihat bagaimana apsek perputaran keuangan yang terlihat dalam aliran uang (cash flow) yang disajikan dalam laporan yang jelas. Jika margin keuntugan sudah didapatkan tetapi aliran uang masih minus maka sebenanya usaha tersebut belum menguntungkan karena masih banyak biaya opersioanl yang dikeluarkan pada bisnis tersebut. Seharusnya jika omset sudah besar maka margin keuntungan juga ikut membesar bukan malah sebaliknya yaitu margin keuntungan masih saja tetap atau malah cenderung menurun.

7. Penyusunan laporan administrasi dan pembukuan, dengan format sederhana mudah dipahami tetapi mampu memberikan informasi yang jelas sesuai kebutuhan. Yang dimaksud dengan laporan administrasi yang jelas adalah kecukupan informasi tertulis terkait aktivitas BUMDes yang dapat dipertanggungjawabkan. Selain itu secara mudah dapat ditemukan dan disediakan ketika diperlukan oleh pihak pihak yang berkepentingan. 


\section{SIMPULAN}

Rangkaian kegiatan pengabdian ini paling tidak membuka wawasan bahwa pengelolaan BUMDes tidak bisa dianggap sederhana. Perlu tatakeloala yang serius agar tujuan pendirian BUMDes dapat tercapai. Dari kegiatan yang sudah dilakukan dapat dismpulkan bahwa:

1. Perlu ditindak lanjuti lagi hasil pendampingan setelah pendampingan ini selesai, untuk melihat apakah konsep yang sudah dipahami dan hasil pendampingan masih dilaksanakan secara berkelanjutan atau tidak. Jika memang diperlukan maka harus dilakukan pendampingan sejenis agar hasil dari pendampingan ini dapat tercapai dengan maksimal.

2. Perlu dukungan kuat dan pemahaman dari kepala desa bahwa proses pengembangan BUMDes tidaklah mudah. Perlu pendampingan khusus baik pendampingan organisasi maupun pendampingan bisnis agar tujuan pendirian BUMDes dapat segera terwujud.

3. Pendampingan ini dapat dilakukan untuk desa lain yang memiliki BUMDes baik yang sudah berjalan maupun yang belum berjalan.

\section{UCAPAN TERIMA KASIH}

Ucapan terimakasih kami sampaikan kepada seluruh jajaran dan pengelola Direktorat Penelitian dan Pengabdian Masyarakat (DPPM) UII, serta seluruh pengelola BUMDes seKecamatan Ngablak termasuk seluruh jajaran pemerintahan Desa Kecamatan Ngablak yang telah berkerjasama dengan kami sehingga program ini bisa terlaksana dengan baik. Ucapan terimakasih juga kami sampaikan kepada seluruh tim pengabdian mulai dari tim pelaksana, tim mahasiswa dan seluruh pihak yang tidak dapat kami sebutkan semuanya yang telah mendukung kegiatan pengabdian ini.

\section{DAFTAR PUSTAKA}

Handayani, Puji, 2009. Manajemen Badan Usaha Milik Desa., Universitas Negeri Malang Hamzah, ArdiM, 2015. Tata kelola Pemerintah Desa., Pustaka 
Kementerian Desa, Pembangunan Daerah Tertinggal Dan Transmigrasi Republik Indonesia. 2019.

Daftar Badan Usaha Milik Desa (BUMDES). Diunduh 2019 Des. Tersedia pada:

http://datin.kemendesa.go.id/simpora/rep_bumdessmry.php

Maria, R R S A. 2016. Peranan Badan Usaha Milik Desa (Bumdes) Pada Kesejahteraan Masyarakat Pedesaan Studi Pada Bumdes Di Gunung Kidul, Yogyakarta. MODUS Vol.28 (2): $155-167$

Nidia, Z. 2018. Kemendes: Jumlah BUMDes Mencapai 41 Ribu Unit. Diunduh 2019 Des. Tersdia pada: https://republika.co.id/berita/ekonomi/korporasi/18/11/26/pissvc383-kemendes-jumlahbumdes-mencapai-41-ribu-unit

Zulkarnain, R. 2014. Urgensi Badan Usaha Milik Desa (BUMDES) Dalam Perekonomian Desa. Fiat Justisia Ilmu Hukum Volume 8 No 3. 